\title{
OPTIMIZATION OF PHOTOCATALYTIC DECOLORIZATION OF THE AZO DYE DIRECT ORANGE 34 BY STATISTICAL EXPERIMENTAL DESIGN
}

\author{
EDUARDO NIEHUES, IEDA S. SCARMÍNIO, KEIKO TAKASHIMA*
}

\author{
Departamento de Química - Centro de Ciências Exatas - Universidade Estadual de Londrina - \\ Caixa postal $6001-86051-990-$ Londrina $-P R$ \\ (Received: July 14, 2009 - Accepted: April 15, 2010)
}

\begin{abstract}
The photodecolorization of the azo dye Direct Orange 34 (DO34) was investigated in $\mathrm{TiO}_{2}$ aqueous suspensions with artificial irradiation at $30^{\circ} \mathrm{C}$. The experimental conditions were optimized by a $2^{5}$ factorial design, using the decolorization percentage after 240 min irradiation as the response. The five factors considered were $\mathrm{DO} 34$ and $\mathrm{TiO}_{2}$ concentrations, stirring speed, air saturation, and adsorption time. The addition of hydrogen peroxide and sodium periodate as oxidants increased the decolorization rate.
\end{abstract}

Keywords: photocatalytic decolorization, Direct Orange $34, \mathrm{TiO}_{2}$, oxidant, factorial design.

\section{INTRODUCTION}

Dyes are an abundant class of colored organic compounds that represent an increasing environmental hazard. During dye production and textile manufacturing processes a large amount of wastewater containing dyestuffs with intense color and toxicity can be introduced into aquatic systems and cause severe ecological and environmental problems. Azo dyes, which are aromatic compounds with one or more azo $(-\mathrm{N}=\mathrm{N}-)$ groups, are the most important and largest class of synthetic dyes used in commercial applications, and they are characterized by azo chromophores ${ }^{1}$. This is a well-known class of dyes of high toxicity which are carcinogenic to animals and humans and not readily degradable. In fact, the discharge of such effluents into the environment is a concern for both toxicological and esthetic reasons ${ }^{2}$. They can cause environmental damage to living organisms by inhibiting the reoxygenation capacity of water and also by blocking sunlight, thereby disturbing the natural growth activity of aquatic life ${ }^{3}$. Therefore, the degradation of organic dyes is necessary from the point of view of public health and safety. Due to the variability of the organic dyes in use, and the corresponding effluents, various treatment methods have been investigated for decontamination purposes including coagulation, chemical oxidation, usually with UV/ozone ${ }^{4,5}, \mathrm{H}_{2} \mathrm{O}$ ${ }_{4,6,7}, \mathrm{H}_{2} \mathrm{O}_{2} / \mathrm{Fe}(\mathrm{II})^{5,8}$, and photocatalytic processes ${ }^{9-11}$, membrane separation, electrochemical processes, and adsorption techniques ${ }^{12,13}$. In recent years, advanced oxidation processes (AOPs) have been extensively employed for the decomposition of hazardous or recalcitrant pollutants in the environment. Photocatalytic oxidation is an alternative means of completely degrading azo dyes ${ }^{14,15}$. The photocatalytic technology combining semiconductors with ultraviolet light is one of the most promising technologies. Semiconductors (e.g., $\mathrm{TiO}_{2}, \mathrm{ZnO}, \mathrm{Fe}_{2} \mathrm{O}_{3}, \mathrm{CdS}$, and $\mathrm{ZnS}$ ) can act as sensitizers for light-reduced redox processes due to their electronic structure, which is characterized by a filled valence band and an empty conduction band ${ }^{9}$. Over the past two decades, the titanium dioxide semiconductor, under UV radiation, has been used in the purification of contaminated waters ${ }^{16}$, because it is non toxic, available at low cost and photochemically stable, and also offers the advantage that solar radiation can be used as the energy source ${ }^{4,17}$. However, in this catalytic process, the production efficiency of the hydroxyl radical in the titanium dioxide may be inhibited due to the excited electron recombination with the conduction band and the hole, formed in the valence band. The introduction of electron receptors such as $\mathrm{ClO}_{3}^{-9}, \mathrm{BrO}_{3}^{-18}, \mathrm{H}_{2} \mathrm{O}_{2}{ }^{4,19}, \mathrm{IO}_{4}^{-20,21}$ and, $\mathrm{S}_{2} \mathrm{O}_{8}{ }^{2-18,22}$ can serve as electron scavengers to prevent the electron-hole recombination and increase the degradation rate ${ }^{16,20}$. On the other hand, inorganic anions such as $\mathrm{Cl}^{-}, \mathrm{SO}_{4}^{2-}, \mathrm{NO}_{3}^{-}, \mathrm{CO}_{3}^{2-}$ affect the photocatalytic activity, inhibiting the degradation due to the reaction of holes and $\mathrm{OH}$ with anions, which behave as scavengers ${ }^{23}$.

A conventional and classical method of studying the decolorization of aqueous dye solutions is the one-factor-at-a-time approach. The major disadvantage of this strategy is that it fails to consider possible interactions between the factors ${ }^{15}$. This limitation of the classical method can be addressed by optimizing all the influencing parameters through statistical experimental design. This is a collection of mathematical and statistical techniques which are useful for developing, improving and optimizing the process and can be used to evaluate the relative significance of several influencing factors, even in the presence of complex interactions. Factorial design ${ }^{15}$ is an experimental strategy that allows the simultaneous manipulation of many factors and possible synergistic and antagonistic interactions between them can be determined. In addition, the development of mathematical models permits an assessment of both the relevance and statistical significance of the factor effects. System optimization can be attained performing a smaller number of experiments than that needed for univariate techniques resulting in lower reagent consumption and considerably less laboratory work. The response surface methodology (RSM) also is an efficient experimental strategy for determining the optimal conditions for a multivariable system rather than optimization using the conventional method, which involves changing one independent variable while keeping the other factors constant.

These methods have been applied in industrial research particularly in situations where a large number of variables influence the system characteristics 22. The principal advantage of this mathematical tool is the reduced number of experiments that are carried out in order to obtain the optimum conditions. The results have been satisfactory in studies that involve the application of factorial design in the photocatalytic degradation of organic compounds such as dyes ${ }^{24}$ and pharmaceutical products ${ }^{25}$.

The application of experimental design and the response surface methodology (RSM) in effluent treatment processes can result in improved decolorization, and reduced process variability, time and overall costs. Additionally, the factors which influence the experiments can be identified and optimized, and the possible synergistic or antagonistic interactions that may exist between factors can be evaluated. However, few recent studies aiming at the optimization of textile dye decolorization are available.

In this study, the photocatalytic decolorization of a mono azo dye Direct Orange 34, DO34 (sodium 4-[(4-aminephenyl)azo] benzene-sulfonate, $\mathrm{C}_{12} \mathrm{H}_{10} \mathrm{~N}_{3} \mathrm{NaO}_{3} \mathrm{~S}$, MW $299.29 \mathrm{~g} \mathrm{~mol}^{-1}, \varepsilon=9.49 \times 10^{3} \mathrm{~L} \mathrm{~mol}^{-1} \mathrm{~cm}^{-1}$ in $410 \mathrm{~nm}$, Fig. 1) was investigated by statistical experimental design. The experimental work was carried out using a $2^{5}$ factorial design in order to examine the main factors affecting photocatalytic decolorization and their interactions. Factors such as azo dye concentration, adsorption time, stirring rate and air saturation were investigated. Also, the addition effects of two oxidants, $\mathrm{H}_{2} \mathrm{O}_{2}$ and $\mathrm{NaIO}_{4}$, on the DO34 decolorization rate were investigated in order to optimize the conditions. 


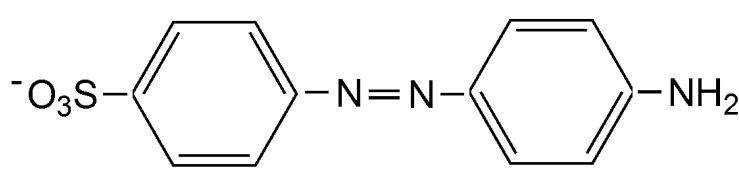

Fig. 1: Molecular structure of the azo dye Direct Orange 34 (DO34).

\section{MATERIALS AND METHODS}

\subsection{Reagents}

The monoazo dye Direct Orange 34 (DO34), CI 40215, $\mathrm{C}_{12} \mathrm{H}_{10} \mathrm{~N}_{3} \mathrm{NaO}_{3} \mathrm{~S}$, was donated by DyStar and used without previous purification; the titanium dioxide, $\mathrm{TiO}_{2}, \mathrm{P}-25$, anatase/rutile $(80 / 20)$, specific area $50 \mathrm{~m}^{2} \mathrm{~g}^{-1}$, was kindly donated by Degussa. A $2.0 \times 10^{-3} \mathrm{~mol} \mathrm{~L}^{-1} \mathrm{DO} 34$ stock solution was prepared using deionized water (USF Elga Maxima), with 30 min of sonication. All the other reagents were of analytical grade: hydrogen peroxide (50-60\%, Nuclear); sodium periodate $(99 \%$, Carlo Erba).

\subsection{Experimental procedure}

The experimental work was carried out using a $2^{5}$ factorial design to examine the main factors influencing the photocatalytic decolorization of a solution of the aqueous dye Direct Orange 34 and their interactions. The experimental conditions for the photocatalytic decolorization are given in Table 1. Following the usual convention, the extreme levels are denoted by minus one (lower level) and plus one (higher level). This, as we shall see, leads to a convenient algorithm for analyzing the experimental results.

Table 1: Factor levels for the $2^{5}$ factorial design.

\begin{tabular}{|c|c|c|c|c|c|}
\hline \multirow[b]{2}{*}{ Label } & \multirow{2}{*}{\multicolumn{2}{|c|}{ Factor }} & \multicolumn{3}{|c|}{ Levels } \\
\hline & & & \multicolumn{2}{|l|}{-1} & 1 \\
\hline 1 & \multicolumn{2}{|c|}{$[\mathrm{DO} 34] / \mathrm{mol} \mathrm{L}^{-1}$} & $1,5 \times 10^{-4}$ & & $2,5 \times 10^{-4}$ \\
\hline 2 & \multicolumn{2}{|c|}{$\left[\mathrm{TiO}_{2}\right] / \mathrm{g} \mathrm{L}^{-1}$} & \multicolumn{2}{|l|}{0,5} & 1,5 \\
\hline 3 & \multicolumn{2}{|c|}{ Agitation/rpm } & \multicolumn{2}{|l|}{420} & 600 \\
\hline 4 & \multicolumn{2}{|c|}{ Air saturation } & \multicolumn{2}{|l|}{ Without } & With \\
\hline \multirow[t]{2}{*}{5} & \multicolumn{2}{|c|}{ Adsorption time/min } & \multicolumn{2}{|l|}{15} & 45 \\
\hline & \multicolumn{5}{|c|}{ Factor levels } \\
\hline Run & 1 & 2 & 3 & 4 & 5 \\
\hline 1 & -1 & -1 & -1 & -1 & -1 \\
\hline 2 & 1 & -1 & -1 & -1 & -1 \\
\hline 3 & -1 & 1 & -1 & -1 & -1 \\
\hline 4 & 1 & 1 & -1 & -1 & -1 \\
\hline 5 & -1 & -1 & 1 & -1 & -1 \\
\hline 6 & 1 & -1 & 1 & -1 & -1 \\
\hline 7 & -1 & 1 & 1 & -1 & -1 \\
\hline 8 & 1 & 1 & 1 & -1 & -1 \\
\hline 9 & -1 & -1 & -1 & 1 & -1 \\
\hline 10 & 1 & -1 & -1 & 1 & -1 \\
\hline 11 & -1 & 1 & -1 & 1 & -1 \\
\hline 12 & 1 & 1 & -1 & 1 & -1 \\
\hline 13 & -1 & -1 & 1 & 1 & -1 \\
\hline 14 & 1 & -1 & 1 & 1 & -1 \\
\hline 15 & -1 & 1 & 1 & 1 & -1 \\
\hline 16 & 1 & 1 & 1 & 1 & -1 \\
\hline 17 & -1 & -1 & -1 & -1 & 1 \\
\hline 18 & 1 & -1 & -1 & -1 & 1 \\
\hline 19 & -1 & 1 & -1 & -1 & 1 \\
\hline 20 & 1 & 1 & -1 & -1 & 1 \\
\hline 21 & -1 & -1 & 1 & -1 & 1 \\
\hline 22 & 1 & -1 & 1 & -1 & 1 \\
\hline 23 & -1 & 1 & 1 & -1 & 1 \\
\hline 24 & 1 & 1 & 1 & -1 & 1 \\
\hline 25 & -1 & -1 & -1 & 1 & 1 \\
\hline 26 & 1 & -1 & -1 & 1 & 1 \\
\hline 27 & -1 & 1 & -1 & 1 & 1 \\
\hline 28 & 1 & 1 & -1 & 1 & 1 \\
\hline 29 & -1 & -1 & 1 & 1 & 1 \\
\hline 30 & 1 & -1 & 1 & 1 & 1 \\
\hline 31 & -1 & 1 & 1 & 1 & 1 \\
\hline 32 & 1 & 1 & 1 & 1 & 1 \\
\hline
\end{tabular}

The DO34 decolorization was carried out inside a wooden chamber $(50 \times 50 \times 50 \mathrm{~cm})$. A borosilicate cylindrical reactor $(200 \mathrm{~mL})$ was placed on a magnetic stirrer (Fisaton 752) and connected to a thermostatic bath with water circulation (Tecnal TE-184). A mercury vapor lamp (125 W) without a bulb (Phillips, HPL-N125), fixed to the central upper part at a $16 \mathrm{~cm}$-distance from the suspension surface, resulted in an irradiation of $0.75( \pm 0.07) \mathrm{mW} \mathrm{cm}^{-2}$ at $365 \mathrm{~nm}$ (Topcon UVR-2). The $\mathrm{TiO}_{2}$ was added to $150 \mathrm{~mL}$ of the dye solution at $30.0( \pm 0.1){ }^{\circ} \mathrm{C}$, under constant agitation $(420 \mathrm{rpm})$ in the dark, at least 15 min before being the sample was submitted to irradiation. The air saturation was carried out using an air compressor (Hobby 14). Aliquots (1.2 mL) were removed at pre-determined times and filtered $(0.22 \mathrm{~mm})$ to remove the $\mathrm{TiO}_{2}$ particles. The $\mathrm{pH}$ was measured and the UV-Vis spectrum recorded (Hitachi U-3000) from 200 to $900 \mathrm{~nm}$ to determine the response, that is, the DO34 decolorization percentage in the region of 360 to $560 \mathrm{~nm}$ for $4 \mathrm{~h}$.

\section{RESULTS AND DISCUSSION}

The analysis of a two-level factorial design begins with the calculation of the main effects of all factors and the interactions between them. All effect values, $E$, were calculated using:

$$
E=\bar{y}_{+}-\bar{y}_{-}
$$

where and $\bar{y}_{-}$represent the averages of results with high $(+)$and low $(-)$ levels, respectively ${ }^{25}$. The signs used in this equation are given in the appropriate column of Table 1 for each factor. For interaction effects the signs are determined by multiplying the signs in the column for the factors involved in the interaction. To reduce the number of experiments, replicates were not performed, and thus a direct calculation of the experimental error and its propagation into effect values cannot be performed. Furthermore, experiments with each factor at a third level, usually the average values of the high and low levels, were not carried out. However, cumulative normal probability plots can be used to determine which effects are statistically significant ${ }^{26}$ and this technique was used here. The normal plot is given in Fig. 2. Cumulative probability plot showed that the main effects of the factors $1(-11.64), 2(12.10)$, $4(-5.29)$ as well as the interaction effect 12 (8.97), calculated by equation 1 , are the most significant ones.

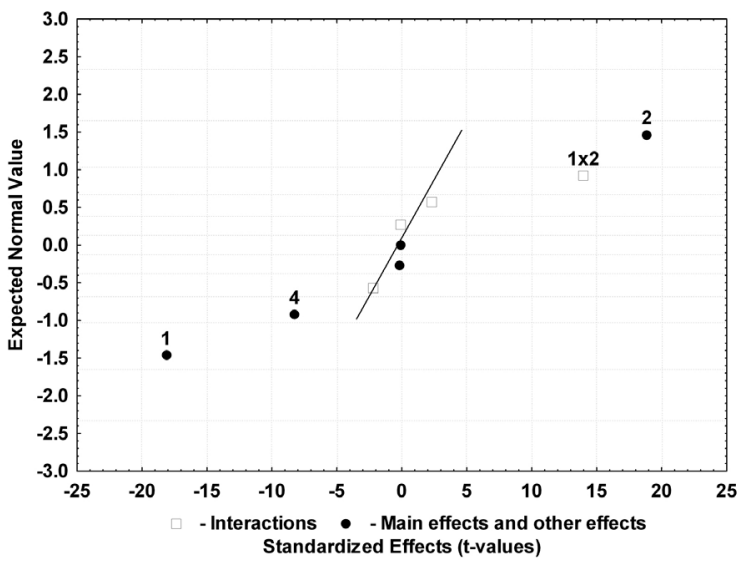

Fig. 2: Normal probability plot of the $2^{5}$ factorial design for the photocatalytic decolorization percentage. Only the effects 1, 2, 4, and 12 are significant.

Increasing the DO34 concentrations from $1.5 \times 10^{-4}$ to $2.5 \times 10^{-4} \mathrm{~mol} \mathrm{~L}^{-1}$ resulted in an average decrease of $11.64 \%$ in the photocatalytic decolorization. This result may be attributed to the fact that at lower dye concentrations considerably more $\mathrm{TiO}_{2}$ particles are available for adsorption ${ }^{11,27,28}$, that is, a significant amount of UV radiation can be absorbed by the dye molecules before reaching the catalyst surface, decreasing the efficiency of the catalytic reaction ${ }^{11,18}$. The yield decrease may also be ascribed to the participation of the adsorbed azo dye on the semiconductor particle in a reversible way in the photosensitized oxidation. Increasing the $\mathrm{TiO}_{2}$ concentration from 0.5 to $1.5 \mathrm{~g} \mathrm{~L}^{-1}$ increased the average photocatalytic decolorization to a lower extent $(12.10 \%)$. The air saturation also decreased the average photocatalytic decolorization (by $5.29 \%$ ), indicating that this process takes place more easily without air saturation or the presence of oxygen. This result was unexpected, because, in principle, the oxygen molecules would capture the photogenerated electrons and would decrease the yield of the electron-hole recombination process, producing the hydroperoxide anion radical (equations 2 and 3) and leaving the photogenerated holes free for hydroxyl radical formation and or substrate oxidation (equations 4 to 6 ) $^{4,9,11}$. Equation 7 establishes that the DO34 could be reacting directly with the holes produced by irradiation with UV light in the semiconductor, through the charge transfer evidenced by the electronic transition at approximately $210 \mathrm{~nm}$ in the UV-Vis spectra, displayed in Fig. 3. 


$$
\begin{aligned}
& \mathrm{e}_{\mathrm{bc}}{ }^{-}+\mathrm{O}_{2(\mathrm{ads})} \longrightarrow \mathrm{O}_{2}{ }^{--} \\
& \mathrm{O}_{2}^{\bullet-}+\mathrm{H}^{+} \longrightarrow \mathrm{HO}_{2}^{\bullet} \\
& \mathrm{h}_{\mathrm{bv}}{ }^{+}+\mathrm{H}_{2} \mathrm{O}_{\text {(ads) }} \longrightarrow{ }^{\bullet} \mathrm{OH}+\mathrm{H}^{+} \\
& \mathrm{h}_{\mathrm{bv}}{ }^{+}+\mathrm{OH}_{(\mathrm{ads})} \longrightarrow{ }^{\bullet} \mathrm{OH} \\
& \mathrm{h}_{\mathrm{bv}}{ }^{+}+\text {dye } \quad \rightarrow \rightarrow \rightarrow \quad \text { oxidation product(s) } \\
& \mathrm{DO} 34_{(\mathrm{ads})}+\mathrm{TiO}_{2}\left(\mathrm{~h}^{+}\right) \longrightarrow \mathrm{TiO}_{2}+\mathrm{DO}^{\circ} 4^{\bullet+}
\end{aligned}
$$

Differently from the solutions behavior, in which it is expected that the air saturation increases the oxygen concentration in the system, the smaller DO34 decolorization with air saturation in heterogeneous system may be attributed to the presence of a lot less reactive nitrogen molecules and argon, that hinder the approximation of the oxygen molecules to the semiconductor surface during the irradiation and decrease the formation of reactive oxygen species. Therefore, the reduction step of the air oxygen by photogenerated electrons to produce less $\mathrm{O}_{2}$ (equation 2) than expected in the conduction band.

The effect of dissolved oxygen was investigated also in the decolorization of the monoazo dye Acid Orange $7(\mathrm{AO} 7)^{29}$ under photolysis and photocatalysis by $\mathrm{ZnO}$ in the presence of $2.5 \times 10^{-2} \mathrm{~mol} \mathrm{~L}^{-1}$ persulfate at $30{ }^{\circ} \mathrm{C}$ in saturated medium with $\mathrm{O}_{2}$ and $\mathrm{N}_{2}$, with and without air saturation, respectively. The highest decolorization rate constant was found when the reaction was carried out in oxygen saturated medium, as expected, followed by no air saturation, air saturation in a similar trend of this work and not totally clear so far, and lastly nitrogen saturation. Tang \& Chen ${ }^{30}$ investigated the effect of dissolved oxygen on the degradation of the azo dye Reactive Black 5 using the $\mathrm{TiO}_{2} /$ UV process under three conditions, that is, with an open reactor, air and $\mathrm{O}_{2}$ saturation respectively. The decolorization was faster when the system was saturated with $\mathrm{O}_{2}$, followed by the other two conditions which gave practically the same results. Habibi et al. ${ }^{31}$ observed that the effect of oxygen on the photocatalytic degradation of the diazo dye Solophenyl Red 3BL (CI direct 80) in the presence of $\mathrm{TiO}_{2}$ was not significant. In this study also the air saturation decreased the azo dye decolorization rate. In this way, the hydroxyl radical could react with DO34 monoazo dye to produce hydroxylated by-products that undergo a breakdown of the azo group and form benzene sulfonic acid and hydroxalated aniline, followed by the benzene and aniline formation that, by successive oxidation, produce aliphatic carboxylic acids that mineralize for $\mathrm{CO}_{2}$ and $\mathrm{H}_{2} \mathrm{O}^{11,32}$.

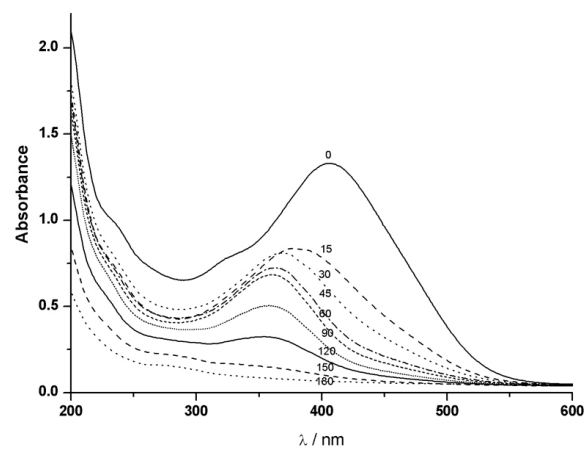

Fig. 3: Spectral changes of DO34 $\left(2.0 \times 10^{-4} \mathrm{~mol} \mathrm{~L}^{-1}\right)$ decolorization and degradation in $\mathrm{TiO}_{2}\left(1.0 \mathrm{~g} \mathrm{~L}^{-1}\right)$ suspension at natural $\mathrm{pH}(7.1)$ and $30.0{ }^{\circ} \mathrm{C}$ during $3 \mathrm{~h}$ irradiation.

The fact that the stirring speed does not change significantly the decolorization percentage could be related to an increase in dissolved oxygen during the stirring, since the decolorization percentage of DO34 decreased with the air saturation. The decolorization rate was not affected by the adsorption time, this may be attributed to the quick rate of sites occupation on the semiconductor surface. On the other hand, the value for the interaction between DO34 and $\mathrm{TiO}_{2}$ concentrations of 8.988 indicates that both concentrations should be altered simultaneously to obtain a greater decolorization of DO34.

Returning to the $2^{5}$ factorial design, since none of these effects involve factors $\mathbf{3}$ and $\mathbf{5}$, it appears that we can consider these factors as inert and analyze the data as a $2^{3}$ factorial design, in replicate, employing the remaining factors. Fitting a model containing linear and second-order interaction terms to the set data, we obtain the equation 8

$$
\hat{y}=\underset{( \pm 0.346)}{65} .58-\underset{( \pm 0.346)}{5.82}[\mathrm{DO} 34]+\underset{( \pm 0.346)}{6.05}\left[\mathrm{TiO}_{2}\right]-\underset{( \pm 0.346)}{2.65} \mathrm{air}+\underset{( \pm 0.346)}{4.48}[\mathrm{DO} 34]\left[\mathrm{TiO}_{2}\right]
$$

which only shows the terms significant at the $95 \%$ confidence level. This equation does not indicate a lack of fit, and explains $97.08 \%$ of the total variation. The analysis of variance (ANOVA) was used to evaluate the goodness of fit. According to the ANOVA results, which are shown in Table 2, the $\mathrm{F}_{\text {statistics }}$ value for the regression was high.

\begin{tabular}{lcccrc}
\multicolumn{6}{l}{ Table 2. ANOVA for $2^{3}$ Factorial Design } \\
\hline Factor & $\begin{array}{c}\text { Sum of } \\
\text { squares }\end{array}$ & $\begin{array}{c}\text { Degrees } \\
\text { of } \\
\text { freedom }\end{array}$ & $\begin{array}{c}\text { Mean } \\
\text { square }\end{array}$ & F-value & Probability \\
\hline (1) $\mathrm{DO} 34^{\text {a) }}$ & 1084.615 & 1 & 1084.615 & 281.6802 & 0.000000 \\
$(2) \mathrm{TiO}_{2}$ & 1172.490 & 1 & 1172.490 & 304.5017 & 0.000000 \\
(3) air & 224.190 & 1 & 224.190 & 58.2234 & 0.000000 \\
1 by 2 & 643.508 & 1 & 643.508 & 167.1223 & 0.000000 \\
1 by 3 & 0.053 & 1 & 0.053 & 0.0137 & 0.907744 \\
2 by 3 & 11.883 & 1 & 11.883 & 3.0860 & 0.091721 \\
Lack of fit & 1.950 & 1 & 1.950 & 0.5065 & 0.483516 \\
Pure error & 92.412 & 24 & 3.851 & & \\
Total SS & 3231.102 & 31 & & & \\
\hline a) Significance probability level.
\end{tabular}

The large value of $\mathrm{F}$ indicates that most of the variation in the response can be explained by the regression model equation. The coded model was used to generate the response surface (Fig. 4).
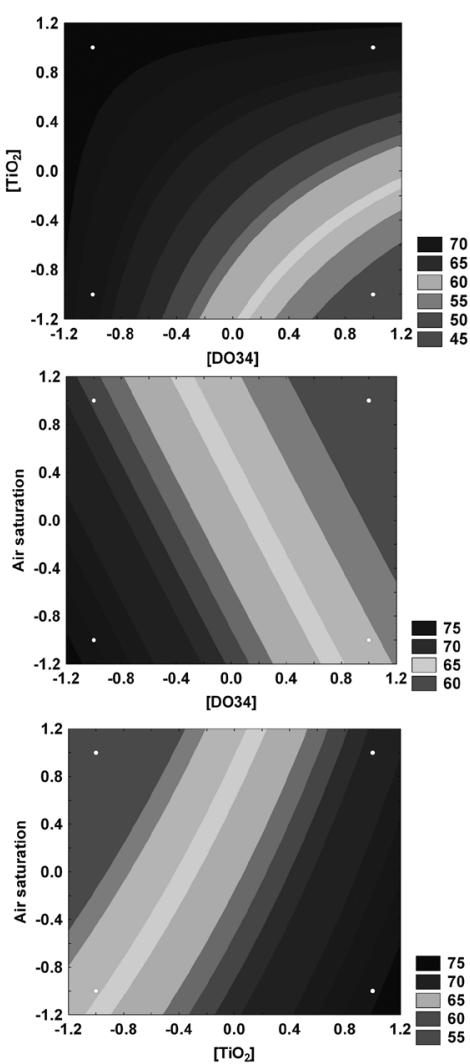

Fig. 4: Response surface contour plot for the photocatalytic decolorization percentage, showing interactive effects between [DO34] and [ $\left.\mathrm{TiO}_{2}\right]$. 
At these levels, according to equation 8 , the photocatalytic decolorization should be close to $75 \%$. An additional experiment was carried out using $2.0 \times 10$ ${ }^{4} \mathrm{~mol} \mathrm{~L}^{-1} \mathrm{DO} 34$ and $1.0 \mathrm{~g} \mathrm{~L}^{-1} \mathrm{TiO}_{2}$, without air saturation, with magnetic stirring of $600 \mathrm{rpm}$ and an adsorption time of $15 \mathrm{~min}$ at $\mathrm{pH} 7.1$ and $30^{\circ} \mathrm{C}$. Under these conditions the DO34 attained a decolorization of $75.0 \%$ in $4 \mathrm{~h}$, and of $95.0 \%$ in $13 \mathrm{~h}$, in a closed reactor and, $94.9 \%$ in $3 \mathrm{~h}$ when the irradiation was carried out inside aluminum foil coverage chamber. Furthermore, it was verified that, under direct photolysis, the decolorization reached $5.1 \%$ in $4 \mathrm{~h}$ in a closed reactor.

\section{Effect of hydrogen peroxide}

The effect of the hydrogen peroxide $\left(\mathrm{H}_{2} \mathrm{O}_{2}\right)$ addition was studied by varying the concentration from 0.1 to $5.0 \mathrm{~g} \mathrm{~L}^{-1}$ under optimized conditions, that is, $2.0 \times 10^{-4} \mathrm{~mol} \mathrm{~L}^{-1} \mathrm{DO} 34$, by direct photolysis and photocatalysis by $\mathrm{TiO}_{2}$, under irradiation of $0.75( \pm 0.07) \mathrm{mW} \mathrm{cm} \mathrm{cm}^{-2}$ for $4 \mathrm{~h}$ at $30^{\circ} \mathrm{C}$, as shown in Fig. 5 .
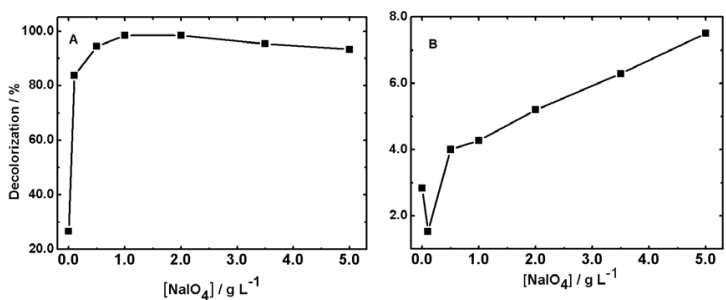

Fig. 5: Effect of the $\mathrm{H}_{2} \mathrm{O}_{2}$ addition in $\mathrm{DO} 34\left(2.0 \times 10^{-4} \mathrm{~mol} \mathrm{~L}^{-1}\right)$ decolorization in the presence (A) and absence (B) of $\mathrm{TiO}_{2}\left(1.0 \mathrm{~g} \mathrm{~L}^{-1}\right)$ at natural $\mathrm{pH}$ and $30^{\circ} \mathrm{C}$.

From this figure it can be observed that the azo dye photolysis in the presence of $\mathrm{H}_{2} \mathrm{O}_{2}$ is not significant, indicating that this oxidant does not produce a sufficient amount of hydroxyl radicals, since the hydrogen peroxide dissociation is more effective at $254 \mathrm{~nm}$ (equation 9) ${ }^{4,6}$. However, in this concentration range the decolorization percentage increased from 4.4 to $8.5 \%$, when the $\mathrm{H}_{2} \mathrm{O}_{2}$ concentration was increased by a factor of 50 from 0.1 to 5.0 $\mathrm{g} \mathrm{L}^{-1}$ :

$$
\mathrm{H}_{2} \mathrm{O}_{2} \stackrel{h v}{\longrightarrow} 2 \cdot \mathrm{OH}
$$

Conversely, in the presence of $\mathrm{TiO}_{2}$ a $75.0 \%$ decolorization of the azo dye DO34 in the absence of $\mathrm{H}_{2} \mathrm{O}_{2}$ was observed in the same period. The addition of 0.1 and $0.5 \mathrm{~g} \mathrm{~L}^{-1}$ of $\mathrm{H}_{2} \mathrm{O}_{2}$ to this suspension increased the decolorization to 84.9 and $89.4 \%$, respectively, remaining almost constant with subsequent additions up to $1.0 \mathrm{~g} \mathrm{~L}^{-1}$. This increase was attributed to hydroxyl radical formation through the capture of photogenerated electrons by the hydrogen peroxide, as shown in equation 10 , decreasing the recombination of the electron-hole pair generated ${ }^{18,19,33}$.

$$
\mathrm{H}_{2} \mathrm{O}_{2}+\mathrm{e}^{-}{ }_{\mathrm{bc}} \longrightarrow \cdot \mathrm{OH}+\mathrm{OH}^{-}
$$

In addition, the hydrogen peroxide may react with the superoxide radical anion $\mathrm{O}_{2}$-(equation 2) to produce $\mathrm{OH}$ (equation 11).

$$
\mathrm{H}_{2} \mathrm{O}_{2}+\mathrm{O}_{2}^{\bullet-} \longrightarrow \cdot \mathrm{OH}+\mathrm{OH}^{-}+\mathrm{O}_{2}
$$

The percentage decrease in the decolorization from 89.4 to $71.4 \%$ when the $\mathrm{H}_{2} \mathrm{O}_{2}$ concentration was increased from 1.0 to $5.0 \mathrm{~g} \mathrm{~L}^{-1}$ may be attributed to the modification of the $\mathrm{TiO}$ surface due to $\mathrm{H}_{2} \mathrm{O}_{2}$ adsorption, scavenging the photogenerated holes and hindering the formation of hydroxyl radicals, thus decreasing its catalytic activity ${ }^{11,30}$. The hole produced in the valence band can oxide the dye molecules in two ways: indirectly through the hydroxyl radical (equation 4) or directly (equation 6). At higher concentrations the $\mathrm{H}_{2} \mathrm{O}_{2}$ begins to compete for the holes, decreasing the availability of $\mathrm{h}_{\mathrm{bv}}{ }^{+}$(equation 12 ).

$$
\mathrm{H}_{2} \mathrm{O}_{2}+2 \mathrm{~h}_{\mathrm{bv}}{ }^{+} \longrightarrow \mathrm{O}_{2}+2 \mathrm{H}^{+}
$$

The excess $\mathrm{H}_{2} \mathrm{O}_{2}$ can also react with the hydroxyl radical to produce another less reactive oxidant, the hydroperoxyl radical (equation 13).

$$
\mathrm{H}_{2} \mathrm{O}_{2}+{ }^{\bullet} \mathrm{OH} \longrightarrow \mathrm{H}_{2} \mathrm{O}+\mathrm{HO}_{2}{ }^{\bullet}
$$

Furthermore, the hydroperoxyl radical can also react with the hydroxyl radical producing water and oxygen (equation 14)

$$
\mathrm{HO}_{2} \cdot{ }^{\bullet} \mathrm{OH} \longrightarrow \mathrm{H}_{2} \mathrm{O}+\mathrm{O}_{2}
$$

Effect of the addition of sodium periodate

The effect of sodium periodate in the DO34 decolorization was investigated by varying the concentration from 0.1 to $5.0 \mathrm{~g} \mathrm{~L}^{-1}$ for a DO34 concentration of $2.0 \times 10^{-4} \mathrm{~mol} \mathrm{~L}^{-1}$, using photolysis and photocatalysis in the presence of $\mathrm{TiO}_{2}$ $\left(1.0 \mathrm{~g} \mathrm{~L} \mathrm{~L}^{-1}\right)$ under irradiation of $0.75( \pm 0.07) \mathrm{mW} \mathrm{cm}^{-2}$ and $30^{\circ} \mathrm{C}$. The variation in the DO34 decolorization percentages are shown in Fig. 6.
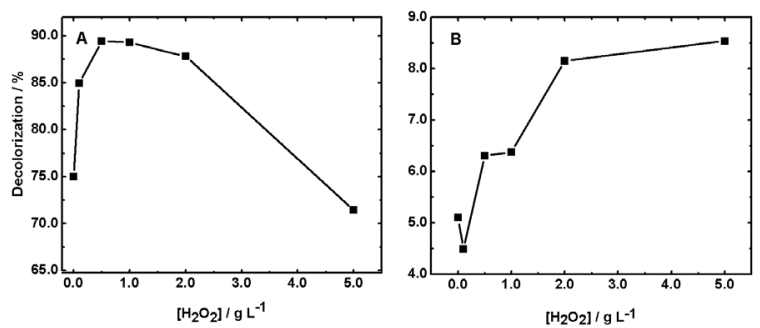

Fig. 6: Effect of the $\mathrm{NaIO}_{4}$ addition in DO34 $\left(2.0 \times 10^{-4} \mathrm{~mol} \mathrm{~L}^{-1}\right)$ decolorization in the presence (A) and absence (B) of $\mathrm{TiO}_{2}\left(1.0 \mathrm{~g} \mathrm{~L}^{-1}\right)$ at natural $\mathrm{pH}$ and $30^{\circ} \mathrm{C}$

In this case, the decolorization rate was much faster, and after $45 \mathrm{~min}$ of irradiation, the decolorization percentage varied from 1.5 to $7.5 \%$ under photolysis in a closed reactor. The 5-fold increase in the decolorization percentage may be attributed to the formation of highly oxidant species such as iodate, $\mathrm{IO}_{3}$, periodate, $\mathrm{IO}_{4}$ and hydroxyl, $\mathrm{OH}$ radicals ${ }^{34}$. The iodate and oxygen anion radicals are produced by periodate anion photolysis (equation $15)^{20,21,35}$

$$
\mathrm{IO}_{4}^{-} \stackrel{h v}{\longrightarrow} \mathrm{IO}_{3}^{\bullet}+\mathrm{O}^{\bullet-}
$$

The oxygen anion radical may react with $\mathrm{H}^{+}$to produce the $\mathrm{OH}$ radical (equation 16) ${ }^{20,21,35}$

$$
\mathrm{O}^{\bullet-}+\mathrm{H}^{+} \rightleftharpoons \cdot \mathrm{OH}
$$

Although the hydroxyl radical has a higher reduction potential $\left(\mathrm{E}^{\mathrm{o}}=2.8 \mathrm{~V}\right)$ in comparison to the oxidant species, such as $\mathrm{IO}_{3}$ and $\mathrm{IO}_{4}$, the availability of hydroxyl radicals to oxide the azo dye molecules may decrease, since this oxidant may react with the periodate anion to yield the $\mathrm{IO}_{4}$ radical, which has a lower oxidation capacity (equation 17).

$$
\cdot \mathrm{OH}+\mathrm{IO}_{4}^{-} \longrightarrow \mathrm{OH}^{-}+\mathrm{IO}_{4}^{\cdot}
$$

Conversely, $26.6 \%$ of the azo dye was decolorized in $45 \mathrm{~min}$ in the presence of $1.0 \mathrm{~g} \mathrm{~L}^{-1} \mathrm{TiO}_{2}$ and $2.0 \times 10^{-4} \mathrm{~mol} \mathrm{~L}^{-1} \mathrm{DO} 34$. The decolorization percentage increased to $83.8 \%$ with the addition of $0.1 \mathrm{~g} \mathrm{~L}^{-1} \mathrm{NaIO}_{4}$. When $0.5 \mathrm{~g} \mathrm{~L}^{-1}$ of $\mathrm{TiO}_{2}$ was added the decolorization reached $94.3 \%$; increasing to $98.4 \%$ for $1.0 \mathrm{~g} \mathrm{~L}^{-1} \mathrm{TiO}_{2}$ and remaining almost constant for $2.0 \mathrm{~g} \mathrm{~L}^{-1}$. The most significant increase in the decolorization percentage being obtained in this medium suggests that, besides the production of oxidant species such as $\mathrm{IO}_{3}, \mathrm{IO}_{4}$ and $\mathrm{OH}$ (equations 15 to 17 ), there is inhibition of the recombination of the electron-hole pair. On the other hand, when the $\mathrm{NaIO}_{4}$ concentration was increased from 2.0 to $5.0 \mathrm{~g} \mathrm{~L}^{-1}$, the decolorization percentage decreased from 98.4 to $93.3 \%$ in $45 \mathrm{~min}$. This behavior suggests that there is competition from the hydroxyl radical at higher concentrations, where the periodate would react with $\mathrm{OH}$ (equation 15), producing a less reactive species, $\mathrm{IO}_{4}{ }^{35}$. Martin et al. ${ }^{36}$ investigated the action mechanism of inorganic oxidants in the $\mathrm{TiO}_{2}$ UV process for chloride hydrocarbon degradation and found that the quantum efficiency of the 4-chlorophenol photooxidation in the presence of $\mathrm{IO}_{4}^{-}$was $0.9 \times 10^{2}$ and $4.8 \times 10^{2}$ in the absence and presence of $\mathrm{TiO}_{2}$, respectively, 


\section{CONCLUSIONS}

Through the relatively small number of experiments was established the experimental conditions for the decolorization of DO34 mono azodye. The decolorization was not affected by the adsorption time in the dark and showed an insignificant change when the stirring speed was changed. $\mathrm{DO} 34$ and $\mathrm{TiO}_{2}$ concentrations displayed the existence of a synergistic influence, while the air bubbling decreased the removal color.

The addition of oxidants such as hydrogen peroxide and sodium periodate for the central point conditions practically doubled the DO34 decolorization with the addition of $0.5 \mathrm{~g} \mathrm{~L}^{-1} \mathrm{H}_{2} \mathrm{O}_{2}$ in $4 \mathrm{~h}$ and $1.0 \mathrm{~g} \mathrm{~L}^{-1} \mathrm{NaIO}_{4}$, in $45 \mathrm{~min}$ irradiation.

\section{AKNOWLEDGMENTS}

The authors are grateful to Fundação Araucária for financial support. E.N. is grateful to $\mathrm{CNPq}$ for the scholarship. The two anonymous reviewers are also thanked for constructive criticism of an earlier manuscript version.

\section{REFERENCES}

1. J.-H. Suna, Y.-K.Wang, R.-X. Suna, S.-Y. Donga, Mater. Chem. Phys. $115,303,(2009)$.

2. Y. Xue, H. Hou, S. Zhu, Chem. Eng. J. 147, 272, (2009).

3. S. Wang, Dyes Pigm. 76, 714, (2008).

4. O. Legrini, E. Oliveros, A.M. Braun, Chem. Rev. 93 671, (1993).

5. M. Pera-Titus, V. Garcia-Molina, M. A. Baños, J. Gimenez, S. Esplugas, Appl. Catal. B 47, 219, (2004).

6. M. A. Behnajady, N. Modirshahla, M. Shokri, Chemosphere 55, 129, (2004).

7. H.-Y. Shu, M.-C. Chang, Dyes Pigm. 65, 25, (2005).

8. H. Kusic, N. Koprivanac, L. J. Srsan, J. Photochem. Photobiol. A 181, 195, (2006).

9. M. R. Hoffmann, S. T. Martin, W. Choi, D. W. Bahnemann, Chem. Rev. $95,69,(1995)$

10. C. Galindo, P. Jacques, A. Kalt, Chemosphere 45, 997, (2001).
11. I. K. Konstatinou, T. A. Albanis, Appl. Catal., B 49, 1, (2004).

12. P. R. Gogate, A. B. Pandit, Adv. Environ. Res. 8, 501, (2004).

13. P. R. Gogate, A. B. Pandit, Adv. Environ. Res. 8, 553, (2004).

14. C. H. Wu, C.L. Chang, C.Y. Kuo, Dyes Pigm. 76, 187, (2008)

15. D. C. Montgomery, Design and analysis of experiments, $4^{\text {th }}$ Ed., John Wiley, New York, 1997.

16. M. Qamar, M. Saquib, M. Muneer, Desalination 186, 255, (2005).

17. M. S. Nahar, K. Hasegawa, S. Kagaya, Chemosphere 65, 1976, (2006).

18. M. Muruganandham, M. Swaminathan, Solar En. Mat. \& Solar Cells 81, 439, (2004).

19. E. Evgenidou, K. Fytianos, I. Poulios, J. Photochem. Photobiol. A 175, 29, (2005).

20. Y. Wang, C. Hong, Water Res. 33, 2031, (1999).

21. L. Yassumoto, J. A. Osajima, K. Takashima, Eclet. Quim. 32, 27, (2007).

22. M. A. Rauf, N. Marzouki, B. K. Korbahtib, J. Hazard. Mater. 159, 602, (2008).

23. N. Kashif, F. Ouyang, J. Environ. Sci. 21, 527, (2009).

24. H.-L. Liu, Y.-R Chiou, Chem. Eng. J. 112, 173, (2005)

25. P. Calza, V. A. Sakkas, A. Villitoti, C. Massolino, V. Boti, E. Pelizzetti, T. Albanis, Appl. Catal. B 84, 379, (2008).

26. B. Barros Neto, I. S. Scarmínio, R. E. Bruns, Statistical Design Chemometrics, $1^{\text {st }}$ ed., Elsevier, Amsterdam, 2006.

27. J. C. Garcia, K. Takashima, J. Photochem. Photobiol. A 155, 215, (2003).

28. S. Sakthivel, B. Neppolian, M. V. Shankar, B. Arabindoo, M. Palanichamy, V. Murugesan, Solar En Mat \& Solar Cells 77, 65, (2003).

29. A.C. Lucilha, K. Takashima, Quim. Nova 32, 1399, (2009)

30. C. Tang, V. Chen, Water Res. 38, 2775, (2004).

31. M. H. Habibi, A. Hassanzadeh, S. Mahdavi, J. Photochem. Photobiol. A 172 (2005) 89-96.

32. M. Sleiman, D. Vildozo, C. Ferronato, J-M. Chovelon, Appl. Catal. B 77, 1 (2007).

33. S. Malato, J. Blanco, C. Richter, B. Braun, M. I. Maldonado, Appl. Catal. B 17, 347, (1998)

34. I. R. Epstein, K. Kustin, J. Phys. Chem. 89, 2275, (1985).

35. C. Lee, J. Yoon, J. Photochem. Photobiol. A 165, 35, (2004).

36. S. T. Martin, A. T. Lee, M. R. Hoffmann, Environ. Sci. Technol. 29, 2567, (1995). 